\title{
Characterization of acoustic detection efficiency using a gliding robotic fish as a mobile receiver platform
}

\author{
Osama Ennasr ${ }^{1 *} \mathbb{D}$, Christopher Holbrook², Darryl W. Hondorp ${ }^{3}$, Charles C. Krueger ${ }^{4}$, Demetris Coleman ${ }^{1}$, \\ Pratap Solanki', John Thon ${ }^{1}$ and Xiaobo Tan ${ }^{1}$
}

\begin{abstract}
Background: Autonomous underwater vehicles (AUVs) and animal telemetry have become important tools for understanding the relationships between aquatic organisms and their environment, but more information is needed to guide the development and use of AUVs as effective animal tracking platforms. A forward-facing acoustic telemetry receiver (VR2Tx 69 kHz; VEMCO, Bedford, Nova Scotia) attached to a novel AUV (gliding robotic fish) was tested in a freshwater lake to (1) compare its detection efficiency (i.e., the probability of detecting an acoustic signal emitted by a tag) of acoustic tags (VEMCO model V8-4H $69 \mathrm{kHz}$ ) to stationary receivers and (2) determine if detection efficiency was related to distance between tag and receiver, direction of movement (toward or away from transmitter), depth, or pitch.

Results: Detection efficiency for mobile (robot-mounted) and stationary receivers were similar at ranges less than $300 \mathrm{~m}$, on average across all tests, but detection efficiency for the mobile receiver decreased faster than for stationary receivers at distances greater than $300 \mathrm{~m}$. Detection efficiency was higher when the robot was moving toward the transmitter than when moving away from the transmitter. Detection efficiency decreased with depth (surface to $4 \mathrm{~m}$ ) when the robot was moving away from the transmitter, but depth had no significant effect on detection efficiency when the robot was moving toward the transmitter. Detection efficiency was higher when the robot was descending (pitched downward) than ascending (pitched upward) when moving toward the transmitter, but pitch had no significant effect when moving away from the transmitter.
\end{abstract}

Conclusion: Results suggested that much of the observed variation in detection efficiency is related to shielding of the acoustic signal by the robot body depending on the positions and orientation of the hydrophone relative to the transmitter. Results are expected to inform hardware, software, and operational changes to gliding robotic fish that will improve detection efficiency. Regardless, data on the size and shape of detection efficiency curves for gliding robotic fish will be useful for planning future missions and should be relevant to other AUVs for telemetry. With refinements, gliding robotic fish could be a useful platform for active tracking of acoustic tags in certain environments.

Keywords: Autonomous underwater vehicles, Underwater glider, Gliding robotic fish, Acoustic telemetry, Detection efficiency

*Correspondence: ennasros@msu.edu

1 Smart Microsystems Lab, Department of Electrical and Computer Engineering, Michigan State University, East Lansing, Ml 48824, USA

Full list of author information is available at the end of the article

\section{Background}

Recent improvements in acoustic telemetry technologies have advanced studies of spatiotemporal ecology and behavior of aquatic organisms [1, 2]. In acoustic telemetry, animals are tagged with acoustic transmitters

c) The Author(s) 2020. This article is licensed under a Creative Commons Attribution 4.0 International License, which permits use, sharing, adaptation, distribution and reproduction in any medium or format, as long as you give appropriate credit to the original author(s) and the source, provide a link to the Creative Commons licence, and indicate if changes were made. The images or other third party material in this article are included in the article's Creative Commons licence, unless indicated otherwise in a credit line to the material. If material is not included in the article's Creative Commons licence and your intended use is not permitted by statutory regulation or exceeds the permitted use, you will need to obtain permission directly from the copyright holder. To view a copy of this licence, visit http://creativeco mmons.org/licenses/by/4.0/. The Creative Commons Public Domain Dedication waiver (http://creativecommons.org/publicdomain/ zero/1.0/) applies to the data made available in this article, unless otherwise stated in a credit line to the data. 
and their movements typically are tracked by stationary networks of hydrophones or acoustic receivers that can identify acoustic-tagged animals in their vicinity [3-6]. Acoustic telemetry enables more frequent observation (or sampling) of individuals than what can be obtained by direct observation or sampling with traditional survey methods (i.e., trawls, gill nets). Observations from such networks have already been used to improve control and assessment of invasive species, gain new insights into spawning behavior and habitat requirements of fish, and describe movements of high-valued stocks $[1,6]$. In the future, telemetry promises to address many critical uncertainties in fishery research and aquatic ecosystems. However, logistical and economic constraints may preclude use of stationary receiver networks to fill gaps in understanding of animal movements, especially in large systems and extreme environments.

Autonomous surface vehicles (ASVs) and autonomous underwater vehicles (AUVs) are becoming more common telemetry assets as receivers can be attached as a payload, or they can be integrated for real-time detection while simultaneously measuring physical and biological properties of the aquatic environment $[7,8]$. For example, robotic sailboats were used to carry acoustic receivers to quantify the spatial distribution of fishes [9], buoyancydriven gliders with integrated or externally mounted receivers have been used to study sturgeon and shark habitats [10-12], stereo-hydrophone acoustic receiver systems have been integrated into propelled AUVs to track and follow leopard sharks [13], and receivers and hydrophones have also been externally mounted and integrated into a propeller-driven AUV [14] and a wave glider for real-time detections of tagged marine life [15].

Each of these vehicles has its unique advantages and disadvantages. Propelled AUVs (e.g., REMUS-100 [14], Woods Hole Oceanographic Institute, Woods Hole, MA, USA, and Iver2 [16], L3Harris OceanServer, Fall River, MA, USA) can overcome large currents and surface waves, and are capable of traveling at higher speeds than other unmanned vehicles. The main drawback for these vehicles is the power requirement needed for the propellers, limiting deployment duration in the field. Another popular class of AUVs are wave gliders, where a surface float that uses wave energy to move forward is attached to an underwater sub via a tether [8]. The energy-efficient nature of wave gliders, such as the Wave Glider (Liquid Robotics, Sunnyvale, CA, USA) used in [15], allows them to be deployed for months at a time. Moreover, accurate positioning of the surface float is readily available through GPS, along with reliable communication for the duration of the mission. In addition to their large size, a limitation of wave gliders is that the environmental sensors deployed on these vehicles need to be tethered to the surface float, limiting the depth monitored by such sensors. Underwater gliders are another class of energyefficient AUVs that travel by changing their buoyancy and center of gravity. Underwater gliders, such as the Slocum glider (Teledyne Webb Research, North Falmouth, MA, USA) [17], have been widely used in a variety of underwater applications [7, 10]. Like wave gliders, the energy-efficient nature of these robots makes them ideal for long-duration missions. However, unlike wave gliders, no tether is involved with these robots, allowing for sampling of water environment at different depths up to the depth rating of the vehicle. The biggest challenges with these robots involve underwater localization and communication because radio-frequency signals do not penetrate water effectively. Thus, vehicle position in between surfacing events relies on dead reckoning, which is susceptible to large errors without the aid of additional sensors such as the Doppler velocity log [18]. As the demand for AUVs to study ecology of fish and other aquatic animals increases, a need exists to understand how design elements, operational characteristics, and environmental conditions influence detection efficiency (defined here as the probability of detecting an acoustic signal emitted by a tag) of telemetry-equipped AUVs.

In this paper, we describe detection efficiency of an acoustic telemetry receiver mounted on a gliding robotic fish, a novel type of underwater AUV [19-21], during a series of field trials in a freshwater lake conducted principally to evaluate hardware and software changes during development. Like underwater gliders, gliding robotic fish (dubbed GRACE, for Gliding-Robot-ACE) achieve locomotion primarily through buoyancy-driven gliding or spiraling. They are also equipped with an active tail fin that can provide extra propulsion (e.g., "swimming" against current), act as a rudder to improve steering during glide/spiral, and improve maneuverability via asymmetrical flapping (e.g., tight turns on the surface or during gliding). Consequently, gliding robotic fish combine the energy-efficient nature of underwater gliders with the high-maneuverability of robotic fish (a type of bio-inspired surface robots) and hence hold great potential in long-duration monitoring of a broad spectrum of aquatic environments. During field tests, we opportunistically collected data on detection efficiency using stationary transmitters and receivers. Objectives were to (1) compare the detection efficiency of the AUV-mounted receiver to that of stationary receivers and (2) determine if the detection efficiency was related to distance between receiver and tag, direction of travel (i.e., toward vs. away from a remote transmitter), robot depth, and pitch during gliding. Results were expected to inform further development of gliding robotic fish and improve the design of AUV-based telemetry performance assessments. 


\section{Methods}

\section{Gliding robotic fish}

An experimental prototype of GRACE, previously used to sample crude oil and harmful algae [20, 22], was modified to serve as a mobile platform for a receiver for detecting acoustic tags. The new robot design featured a carbon fiber shell with removable front section, and aluminum wings and tail. Sensor payloads consisted of a dissolved oxygen and temperature sensor (In-Situ RDO Pro-X, Fort Collins, CO USA), an underwater quantum sensor (LICOR LI-192, Lincoln, NE USA) for measuring Photosynthetically Active Radiation, a Chlorophyll sensor (Turner Designs Cyclops-7F C, San Jose, CA USA) and a freshwater Blue Green Algae sensor (Turner Designs Cyclops-7F $\mathrm{P})$. The sensors were bundled and connected to the robot electronics through a waterproof connector (MarcArney SubConn MCIL16-F/M, Esbjerg, Denmark).

A GPS sensor (Garmin GPS $18 \times$ LVC, Olathe, KS USA) was used for robot localization when the robot was on the surface, while a pressure sensor (Honeywell 40PC100G2A, Charlotte, NC USA) was used to measure the robot depth underwater. Two linear actuators were used for buoyancy and pitch control; in particular, one pushed water in and out of a tank for buoyancy control, and the other moved a mass backward and forward to pitch the robot up or down. These actuators were controlled, at a low level, by an embedded microcontroller (MCU) that operated at 7.37 MHz. The same microcontroller handled the reading of sensor data. An XBee wireless serial interface was used for communication with a laptop on a boat located within the communication range (typically several hundred meters). This channel was used to send commands to the robot or query data from the robot when it was on the surface (see summary of robot components and specifications in Table 1).

Hardware and software design of the robot underwent some evolution during the study period. In the 2016 trial, all robot operations (i.e., control, communication, and data processing) were implemented on the embedded MCU, and the robot sent its GPS position along with a UTC time-stamp over the XBee channel every 5 $\mathrm{s}$ whenever it was on the surface. When the robot performed a dive, it temporarily stored depth data that were time-stamped and sent through the XBee channel upon surfacing. In 2017, the robot also temporarily stored orientation (yaw, pitch, and roll angles) information whenever it was underwater. In 2018, we incorporated a Raspberry Pi Zero W that performed high-level tasks such as communication and data storage. This modification allowed us to complement the original broadcasted messages by storing all available data onto an on-board SD card every $5 \mathrm{~s}$. These data consisted of GPS coordinates and UTC time, environmental sensor readings, orientation of the robot (yaw, pitch, and roll angles), positions of each actuator, and battery level.

\section{Field tests}

A self-contained acoustic receiver (VEMCO model VR2Tx; 69 kHz; Bedford, Nova Scotia, Canada) was attached to the robot, and field trials were conducted in

Table 1 GRACE components and specifications

\begin{tabular}{|c|c|}
\hline Component & Description \\
\hline Hull dimensions & $103 \times 20 \times 30 \mathrm{~cm}(\mathrm{~L} \times \mathrm{W} \times \mathrm{H})$ \\
\hline Tail-to-nose length & $140 \mathrm{~cm}$ \\
\hline Wingspan & $60 \mathrm{~cm}$ \\
\hline Weight & $20 \mathrm{~kg}$ \\
\hline Robot hull material & Carbon fiber \\
\hline Battery capacity & $\begin{array}{l}555 \text { W H Li-ion polymer (approx. } 5 \text { days of continuous actuation with } 1400 \\
\text { dive cycles @ 5-min intervals) }\end{array}$ \\
\hline Processors & Raspberry Pi Zero W, Microchip dsPIC30F6014A MCU \\
\hline Communication & XBee \\
\hline Positioning & GPS and pressure sensor \\
\hline Orientation & VN100S IMU and attitude and heading reference system \\
\hline Buoyancy tank volume & $190 \mathrm{~mL}$ \\
\hline Pitch control ${ }^{\mathrm{a}}$ & $+40^{\circ}$ (pitching up), $-25^{\circ}$ (pitching down) \\
\hline Average swimming speed & $25 \mathrm{~cm} / \mathrm{s}$ \\
\hline Average glide speed & $13 \mathrm{~cm} / \mathrm{s}$ (as low as $5 \mathrm{~cm} / \mathrm{s}$ against current and a high of $35 \mathrm{~cm} / \mathrm{s}$ with current) \\
\hline Environmental sensors & $\begin{array}{l}\text { Dissolved oxygen and temperature, photosynthetically active radiation, } \\
\text { freshwater blue green algae, chlorophyll }\end{array}$ \\
\hline
\end{tabular}

a Due to fabrication and balancing imperfections, the magnitude of the pitch angle when pitching down is smaller than that for pitching up 
Higgins Lake, Michigan, USA, during 2016-2018. The receiver was mounted at the bottom of the robot, facing forward (Fig. 1). Detection efficiency was investigated as a function of distance between a test transmitter, or 'tag', and the receiver, robot direction (toward or away from tag), robot depth, and robot pitch. Each receiver also measured temperature (internal), tilt (degrees from vertical), and environmental acoustic noise $(69 \mathrm{kHz})$ every $10 \mathrm{~min}$, but those variables were not used in analyses (see Additional file 1) due to insufficient sampling frequency to describe within-dive variation (temperature, noise, and tilt); inability to detect rapid changes during dives (temperature); and high correlations (redundancy) with robot-integrated sensor data (tilt).

Tests ('runs') were conducted on 11 November 2016, 3 November 2017, and 14-15 June 2018 in Higgins Lake, Michigan, where water depths ranged between 10-20 m (Fig. 2; Table 2). These locations were selected to facilitate field testing of navigation and actuation systems on a given day and not necessarily with detection efficiency tests in mind. While these tests were primarily focused on assessing the robot's capabilities and identifying necessary improvements, we used these opportunities to determine the parameters that affect detection efficiency for underwater gliders. During each trial, an acoustic transmitter (VEMCO model V8-4H $69 \mathrm{kHz}$; source power level $147 \mathrm{~dB}$ re 1 Pa $\mu$ @ $1 \mathrm{~m}$ ) was deployed on a stationary mooring (depth ranged 1.5-7.0 m among runs) and emitted a uniquely encoded signal every $24 \mathrm{~s}$. Transmitted signals were encoded using VEMCO's $69-\mathrm{kHz}$ pulse-position-modulation scheme (VEMCO code space A69-1601). Once decoded, each signal's unique ID was recorded on the receiver along with time of detection. This tag type was used because it provided a detection range amenable to the field evaluation of the robot in the study system. Specific tag programming (24 s transmit interval) was selected to ensure that testing would provide sufficient sample size for regression models and

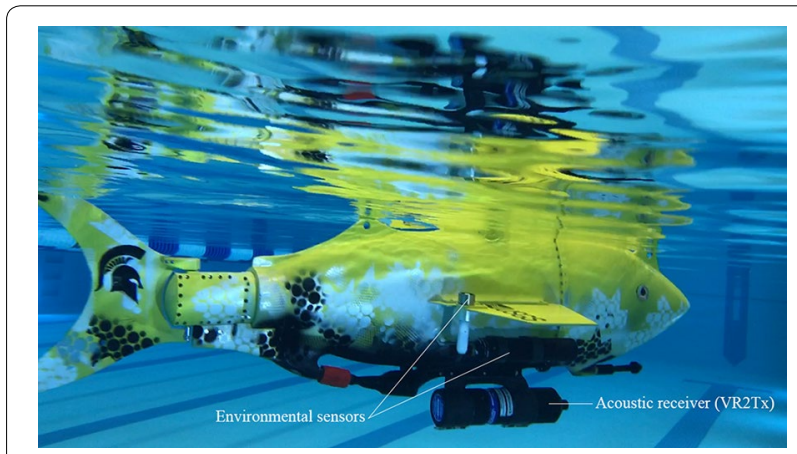

Fig. 1 Gliding robotic fish. The modified version of GRACE with bottom-mounted telemetry receiver to capture relatively fine-scale changes in variables of interest (e.g., depth, pitch).

For every test, a target GPS waypoint was sent to the robot from a laptop on a boat over the wireless communication channel, and the robot was tasked with navigating to that location through a series of dives. A depth of $4.5 \mathrm{~m}$ was used as the maximum diving depth for the robot as the depth rating had not been established for the robot hull. Each dive was completed in approximately $3 \mathrm{~min}$ on average. Robot heading was controlled by changes in tail position such that the tail acted as a rudder during gliding to maintain course toward the target location. Between dives, the robot remained on the surface for $20 \mathrm{~s}$ to ensure that a GPS lock was established, and a new GPS position was obtained to calculate the desired heading angle.

\section{Mobile detection efficiency tests}

In 2016, the effect of distance between receiver and tag on detection efficiency was evaluated and compared between mobile and stationary receivers (objective \#1) by navigating the robot-receiver system along a line of five stationary receivers (VEMCO model VR2Tx $69 \mathrm{kHz}$ ). Stationary receivers were suspended $1.5 \mathrm{~m}$ below the surface (in the hydrophone-up position) and moored via rope to weights on the lake bottom. Water depth at stationary receiver sites ranged between 7.3 and $10.0 \mathrm{~m}$. Stationary receivers were arranged in a line with the transmitter such that the receivers were spaced 200,400, 600,800 , and $1000 \mathrm{~m}$ from the transmitter, which was suspended $1.5 \mathrm{~m}$ below the surface in $11.0 \mathrm{~m}$ water depth. During the first trial (run 16-1), the robot began navigating $996 \mathrm{~m}$ from the transmitter, in a direction roughly parallel to the line of stationary receivers and toward the transmitter. As the trial progressed, winds (approximately $4.9-5.8 \mathrm{~m} / \mathrm{s}$, based on a regional model) moved the robot off-course while it attempted to obtain a GPS fix. Magnetic disturbance, resulting from the internal electronics and actuators, which affected the stability of the measured heading angle using the on-board Inertial Measurement Unit (IMU), also contributed to the robot veering off-course. Consequently, the robot was removed from water about $563 \mathrm{~m}$ from the transmitter, and then returned to the water for a second trial (run 16-2). During the second trial, the robot started $411 \mathrm{~m}$ away from the tag, and was removed from the water $288 \mathrm{~m}$ from the transmitter.

Prior to the next field test, robot navigation problems observed in 2016 were addressed. First, the IMU was calibrated to reject larger magnetic disturbances, which improved the stability of the measured heading angle. Additionally, to combat high winds, the robot was tasked 


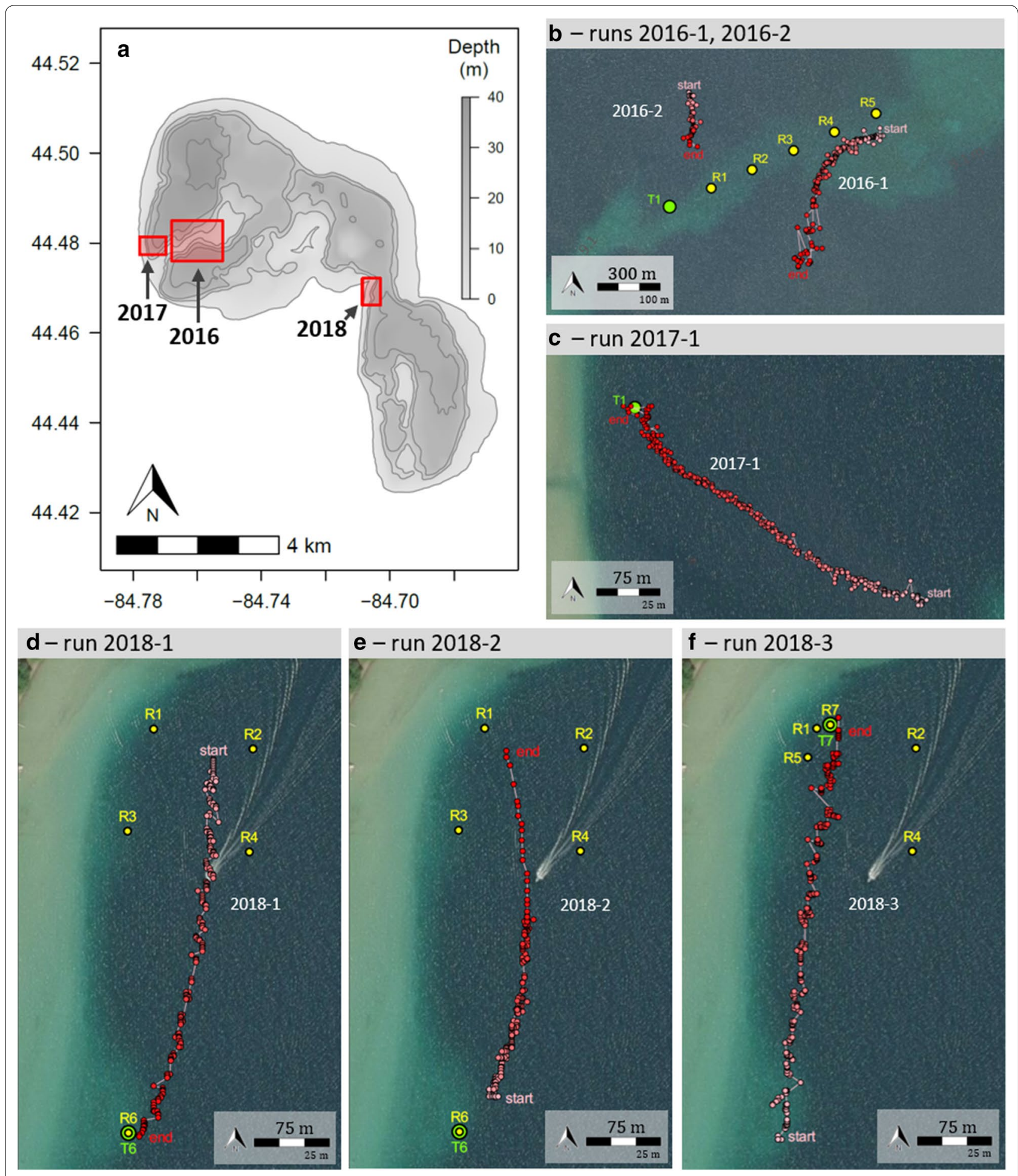

Fig. 2 Lake tests. a Map of Higgins Lake, Michigan, showing regions (red rectangles) where gliding robotic fish GRACE was tested 11 Nov 2016 (b), 03 Nov 2017 (c), and 14-15 June 2018 (d-f) with stationary transmitter locations (green circles), stationary receiver locations (yellow circles), and GPS locations (pink/red circles) recorded by the gliding robotic fish during each run. GPS points are shaded along a gradient from start (pink) to end (red) of each run 
Table 2 Summary of mobile detection efficiency trials with GRACE at Higgins Lake in 2016, 2017, and 2018 (Tag location refers to sites identified in Fig. 2)

\begin{tabular}{|c|c|c|c|c|c|c|c|c|}
\hline \multirow[t]{2}{*}{ Run ID } & \multicolumn{2}{|c|}{ Date time (UTC-4) } & \multirow[t]{2}{*}{ Tag location } & \multicolumn{2}{|c|}{$\begin{array}{l}\text { Distance from tag } \\
\text { (m) }\end{array}$} & \multirow[t]{2}{*}{ Mean heading (deg.) } & \multirow[t]{2}{*}{$\begin{array}{l}\text { Wind speed } \\
(\mathrm{m} / \mathrm{s})\end{array}$} & \multirow[t]{2}{*}{ Wind heading (deg.) } \\
\hline & Start & End & & Start & End & & & \\
\hline $16-1$ & $\begin{array}{l}11 / 11 / 16 \\
10: 47\end{array}$ & $\begin{array}{l}11 / 11 / 16 \\
12: 38\end{array}$ & $\mathrm{~T} 1$ & 996 & 563 & $219^{\circ}(\mathrm{SSW})$ & 5.8 & $187^{\circ}(\mathrm{S})$ \\
\hline $16-2$ & $\begin{array}{l}11 / 11 / 16 \\
12: 52\end{array}$ & $\begin{array}{l}11 / 11 / 16 \\
13: 30\end{array}$ & $\mathrm{~T} 1$ & 411 & 288 & $214^{\circ}(\mathrm{SSW})$ & 4.9 & $182^{\circ}(\mathrm{S})$ \\
\hline $17-1$ & $\begin{array}{l}11 / 3 / 17 \\
12: 45\end{array}$ & $\begin{array}{l}11 / 3 / 17 \\
14: 54\end{array}$ & $\mathrm{~T} 1$ & 389 & 8 & $303^{\circ}(\mathrm{WNW})$ & 4.2 & $148^{\circ}(\mathrm{SE})$ \\
\hline $18-1$ & $\begin{array}{l}6 / 14 / 18 \\
18: 06\end{array}$ & $\begin{array}{l}\text { 6/14/18 } \\
19: 00\end{array}$ & T6 & 360 & 11 & $191(S)$ & 4.1 & $163^{\circ}(\mathrm{SSE})$ \\
\hline $18-2$ & $\begin{array}{l}6 / 14 / 18 \\
19: 20\end{array}$ & $\begin{array}{l}6 / 14 / 18 \\
21: 13\end{array}$ & T6 & 44 & 361 & $3^{\circ}(\mathrm{N})$ & 1.7 & $157^{\circ}(\mathrm{SE})$ \\
\hline $18-3$ & $\begin{array}{l}6 / 15 / 18 \\
10: 06\end{array}$ & $\begin{array}{l}6 / 15 / 18 \\
11: 09\end{array}$ & $\mathrm{T7}$ & 408 & 10 & $8^{\circ}(\mathrm{N})$ & 1.9 & $324^{\circ}(\mathrm{NW})$ \\
\hline
\end{tabular}

Mean heading reflects the bearing from the first GPS measurement toward the last GPS measurement in each run. Wind speed and direction (heading; note that this is the direction the wind vectors are following, not "blowing from" as is customary) are coarse-scale regional estimates based on the NCEP's Global Forecast System, as described in methods

with "swimming" (by continuously flapping its tail) on the surface while waiting for a GPS fix.

After these corrections, a second field trial was carried out in 2017 to further investigate the effect of distance on the detection efficiency for a mobile receiver (objective \#1). During this trial (run 17-1), the gliding robotic fish navigated from $389 \mathrm{~m}$ to less than $1 \mathrm{~m}$ from the tag, in a direction roughly northwest. The tag was suspended $3.0 \mathrm{~m}$ below the surface in $19.8 \mathrm{~m}$ water depth. Stationary receivers were not deployed during the test in 2017 due to logistical constraints. While the windspeeds during this trial were close to those in 2016 (approximately $4.2 \mathrm{~m} / \mathrm{s}$, based on regional model), the provisions we took with surface swimming allowed the robot to complete its task. During navigation, the tag transmitted 323 times and the robot repeatedly ascended and descended between the surface and $4.5 \mathrm{~m}$ depth.

A third set of field trials were conducted in 2018 to investigate the effect of the robot's direction of travel, depth, and pitch on detection efficiency (Objective \#2). In addition, four stationary receivers (R1-R4; Fig. 2) were deployed in roughly a square-shaped pattern to explore the utility of obtaining fine-scale robot tracks using timedifference-of-arrival-based positioning (not evaluated in this paper). Stationary receivers were suspended vertically (hydrophone up) 4.7-19.8 m below the surface in 9.3-24.0 m water depth. A fifth stationary receiver was collocated with the stationary tag; both were suspended vertically (hydrophone up) $4.6 \mathrm{~m}$ below the water surface in $9.1 \mathrm{~m}$ water depth. The robot was tasked with navigating toward the tag during two runs (runs 18-1, 18-3) and away from the tag during one run (run 18-2). Like the trials in 2017, the robot was tasked with swimming while awaiting a GPS fix on the surface to counteract surface waves that could push the robot away from its desired course.

Water current and wind data (e.g., velocity and direction) were not measured at the site during testing, but regional wind data were obtained from NCEP's Global Forecast System [23] using the R package RWind. Modelbased estimates of mean wind speed and direction during 3-h intervals (e.g., 00:00-02:59 UTC, 03:00-05:59 UTC) at $10 \mathrm{~m}$ above land surface were obtained for two locations about $24 \mathrm{~km}$ west $\left(85.0^{\circ} \mathrm{W}, 44.5^{\circ} \mathrm{N}\right)$ and $17 \mathrm{~km}$ east $\left(84.5^{\circ} \mathrm{W}, 44.5^{\circ} \mathrm{N}\right)$ of the study site. Mean speed and direction between the two locations were used to represent conditions at the study site during the 3-h interval that contained each run.

\section{Data analysis}

Transmitter detection efficiency curves were estimated for stationary and mobile receivers using generalized additive models (GAMs) with binomial error structure. GAMs were used because they relax distributional assumptions and allow greater flexibility in modeling non-linear responses than generalized linear models [24]. Times of missed detections (i.e., transmitted but not detected) were estimated by sequencing every $24 \mathrm{~s}$ through each detection data set to identify time stamps that were not in the detection file for the receiver. A binary indicator variable was used to represent detection (1) or non-detection (0). Variables describing robot location and orientation (i.e., latitude, longitude, depth, pitch) and water temperature (see Additional file 1) were 
estimated at time of each detection or non-detection using time-based linear interpolation over measurements recorded by the robot (Figs. 3, 4). Detection efficiency curves were first described separately for each run and for stationary and mobile receivers during each run, by fitting a GAM to data from each run separately, except that runs 16-1 and 16-2 were combined. These GAMs simply estimated the probability of detection (binomial response) as a function of distance between tag and receiver (Fig. 5). Specifically, each model estimated the log-odds (logit) of the probability of detecting each transmitted tag signal as a function of the predictors:

$$
\operatorname{logit}(p)=b_{0}+s_{r t \_d i s t}+\varepsilon,
$$

where $b_{0}$ is the intercept; $s_{r t}$ dist:dir is a smoothed function of distance for each direction and run, and $\varepsilon$ is error assumed from an independent draw from a normal

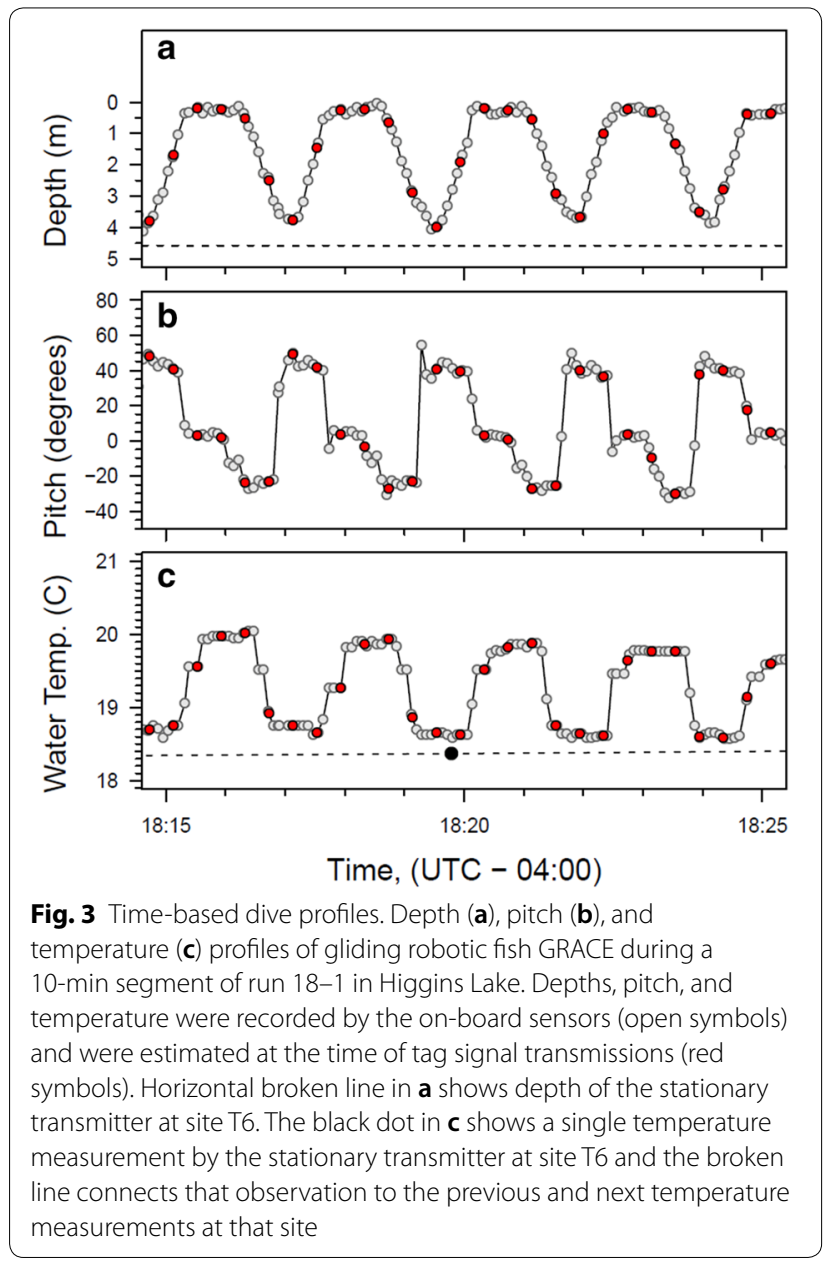

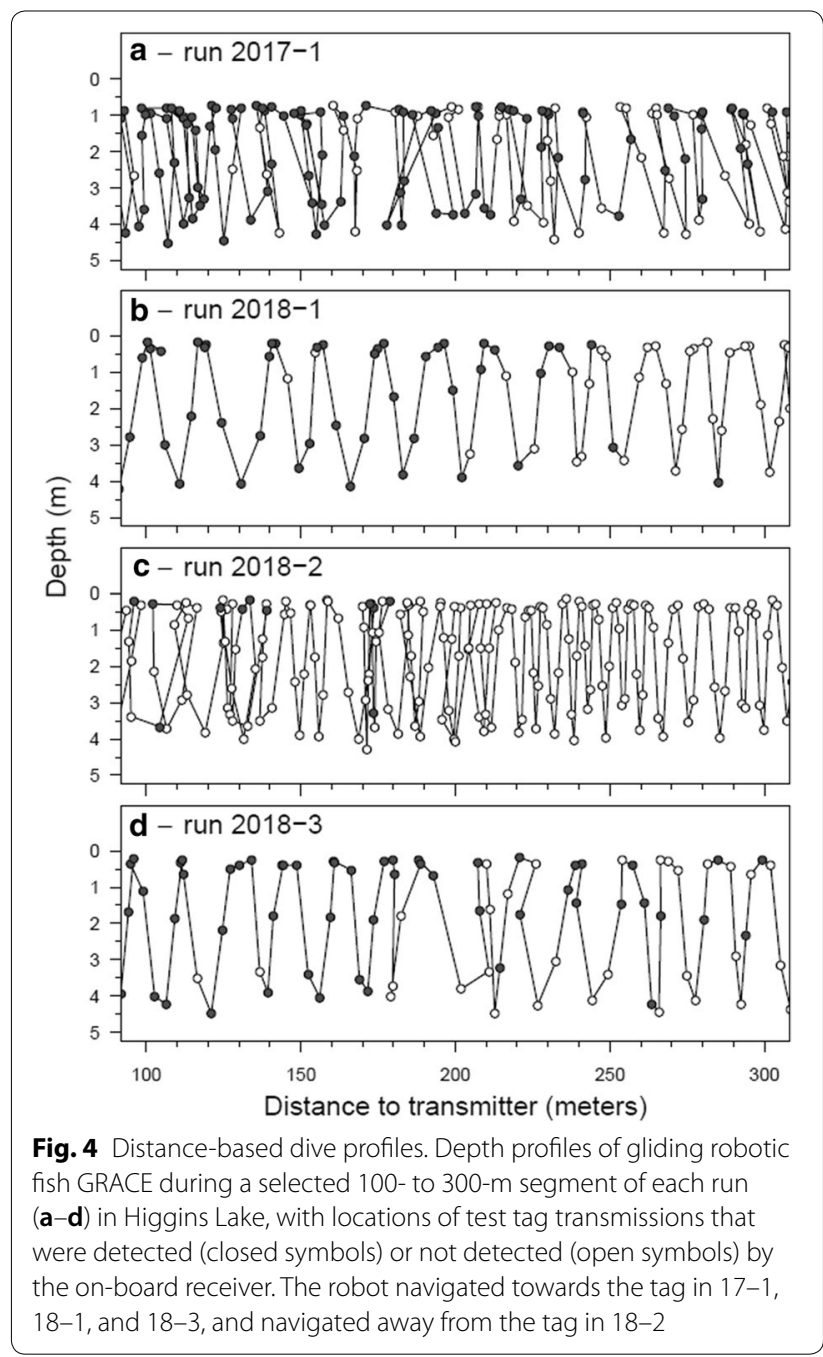

distribution with mean 0 and variance $\sigma^{2}$. All models were fit to data using the 'gam' function in the $\mathrm{mgcv}$ library (v. 1.8.31) [25] in $R(v$. 3.6.2) [26]. The basis for smoothing functions was a cubic regression spline (bs = "cr" in mgcv) and 10 knots.

A GAM was fit to the data from runs $17-1,18-1$, $18-2$, and $18-3$ to estimate the detection efficiency as a function of distance between receiver and transmitter, direction of robot relative to transmitter (toward, away), robot depth (meters below water surface), and robot pitch (degrees from horizontal). Runs 16-1 and 16-2 were not included in the model because (1) little overlap occurred in distances covered between those runs and others (Fig. 5); (2) they lacked pitch data; and (3) depth data were incomplete during those runs. Specifically, the 


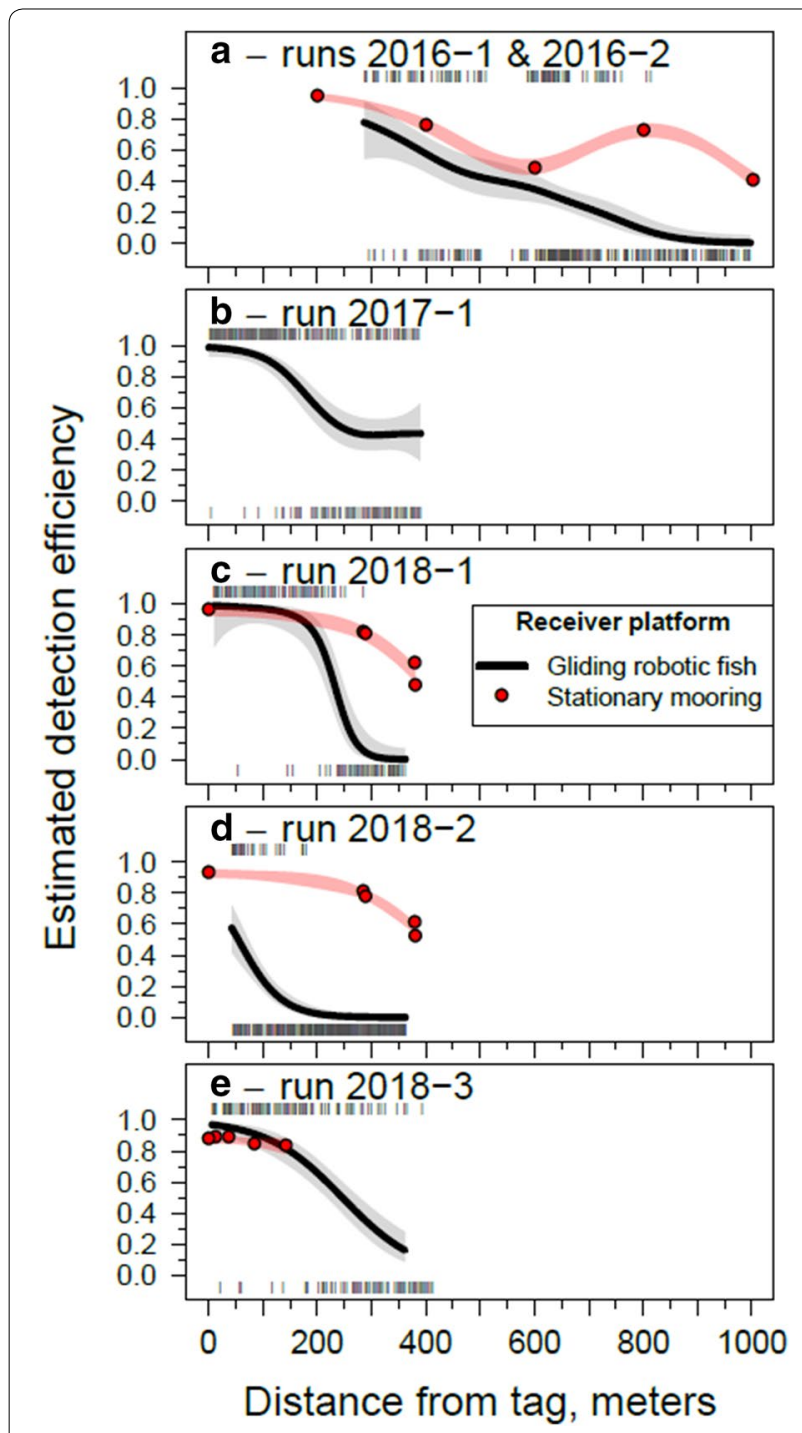

Fig. 5 Detection efficiency as a function of distance for mobile and stationary receivers. Estimated detection efficiencies for acoustic receivers affixed to stationary moorings (red symbols are fitted values; red shaded regions are GAM-based 95\% confidence regions) and gliding robotic fish GRACE (black lines are fitted values; gray-shaded regions are GAM-based 95\% confidence regions) in Higgins Lake, Michigan, during field tests in 2016 (a), 2017 (b), and 2018 (c-e). Vertical gray bars show distances between robot and the transmitter when each coded signal was detected (1) or not detected (0)

model estimated the log-odds (logit) of the probability of detecting each transmitted tag signal as a function of the predictors are smoothed functions of depth and pitch for each direction; and $\varepsilon$ is error assumed from an independent draw from a normal distribution with mean 0 and variance $\sigma^{2}$. Direction-specific smoothers were included to estimate the partial effects of each level of each continuous predictor on the response (detection efficiency). The run-specific smoother for distance was included to account for run-specific variability in detection efficiency not explained by other predictors. To eliminate confounding between run and direction, effects of direction were limited to contrast between runs $18-1$ and $18-2$, which occurred on the same day, and was accomplished by treating runs $18-1$ and $18-2$ as a single run (" $18-1$ \& 18-2") in the model. Thus, we assumed that differences between runs $18-1$ and 18-2 were attributed to change in direction relative to tag and no other variables or conditions. This assumption was supported by similar detection efficiency curves as functions of distance for stationary receivers during those runs (Fig. 5c, d).

Run-specific variation could have been treated as a random effect in a mixed-effects model, but we anticipated no benefit of a mixed model with only four unique runs. An added advantage of a run-specific smoother is that it allows exploration of the unique shape of each curve that might inform future hypotheses about variables influencing the shape of the curve during each run. While it is possible that some across-run variation could be explained by wind, ambient noise, or water temperatures, our observational data set did not have replicate runs (wind, water temperature) or sufficient within-predictor contrast (ambient noise) and thus we did not include those variables in the model. Rather, we used those observations to generate hypotheses from our descriptive analyses.

The basis for all smoothing functions was a cubic regression spline with shrinkage (bs $=$ "cs" in mgcv) and 10 knots. "Shrinkage smoothers" allow identification of non-significant smoothers that essentially carry no weight in the model by reducing the effective degrees of freedom to a value as small as zero [24]. Thus, shrinkage smoothers are an alternative to stepwise model selection procedures. All smoothers were estimated using restricted maximum likelihood. Prior to model fitting, data were checked for evidence of collinearity (correlations among predictors). Model fit was evaluated by checking for concurvity (non-independence) among smoothers and evidence of non-normality among residuals. Significance of each smoothing term was determined

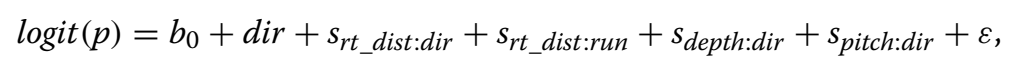

where $b_{0}$ is the intercept; dir is the fixed effect of direction; $s_{r t \_d i s t: d i r}$ and $s_{r t}$ dist:run are smoothed functions of distance for each direction and run; $s_{\text {depth:dir }}$ and $s_{\text {pitch:dir }}$ based on estimated degrees of freedom and approximate $p$-value for the null hypothesis that the smoothing term was zero. The significance level for all tests was 0.05 . 
Table 3 Summary of parametric coefficients (linear terms) and smoothing terms from GAM used to determine if detection efficiency was related to distance from transmitter (tag distance, in meters), direction of robot travel relative to transmitter (toward or away), robot depth (depth, in meters from water surface), or robot pitch (pitch, in degrees from horizontal)

\begin{tabular}{|c|c|c|c|c|}
\hline Linear terms & Estimate & SE & $Z$ & $p$-value \\
\hline (Intercept) & -4.282 & 0.581 & -7.363 & $1.79 E-13$ \\
\hline dir $=$ toward & 5.322 & 0.594 & 8.965 & $3.11 E-19$ \\
\hline Smoothing terms & EDF & & $x^{2}$ & $p$-value \\
\hline s(rt_distance): dir=away & $6.48 \mathrm{E}-04$ & & $4.85 \mathrm{E}-04$ & 0.265 \\
\hline $\mathrm{s}\left(\mathrm{rt} \_\right.$distance $):$dir $=$toward & 1.642 & & 4.345 & $5.84 E-04$ \\
\hline s(rt_distance): run $=17-1$ & 2.152 & & 6.651 & $3.07 E-04$ \\
\hline $\mathrm{s}(\mathrm{rt}$ distance): $r u n=18-1,18-2$ & 2.466 & & 44.738 & $4.25 E-13$ \\
\hline $\mathrm{s}\left(\mathrm{rt} \_\right.$distance $): r u n=18-3$ & 1.118 & & 2.699 & $5.27 E-03$ \\
\hline$s($ pitch): dir = away & 0.570 & & 1.087 & 0.152 \\
\hline$s($ pitch $):$ dir = toward & 2.416 & & 33.366 & $3.15 E-09$ \\
\hline s(depth): dir=away & 1.212 & & 9.468 & $8.55 E-04$ \\
\hline s(depth): dir = toward & 0.209 & & 0.255 & 0.247 \\
\hline
\end{tabular}

Included for each parametric coefficient is the estimate, standard error (SE), test statistic ( $Z$ ), and $p$-value for the null hypothesis that the corresponding parameter is zero. Included for each smoothing term is the estimated degrees of freedom (EDF), test statistic ( $\left.\chi^{2}\right)$, and approximate $p$-value for the null hypothesis that the smoothing term is zero. Italicized $p$-values are significant at significance level of 0.05

Partial effects plots were used to assess the influence of each smoother on the log-odds of detection efficiency at each level of the predictor. Plots of fitted values were used to assess the influence of each predictor on detection efficiency during each run on the probability scale.

\section{Results}

Estimated detection efficiency of the robot-mounted receiver was lower than concurrently operated stationary receivers during all three runs where stationary receivers covered the full range of mobile runs (Fig. 5 a, c, d). Scale and shape of detection efficiency curves, when plotted against distance between transmitter and receiver, varied among runs for both stationary and mobile receivers. During 2016, when detection efficiencies were higher at longer distances for both stationary and mobile receivers than during any other run, detection efficiencies for the mobile receiver were only slightly lower than the stationary receivers up to $600 \mathrm{~m}$ from the transmitter, but substantially lower at $800 \mathrm{~m}$ and $1000 \mathrm{~m}$. The shape of the curve for the stationary receivers was unexpected (e.g., higher efficiency at $800 \mathrm{~m}$ than $600 \mathrm{~m}$ ), and suggested that these stationary receivers were affected by processes that were not quantified. During 18-1, estimated detection efficiency was similar between stationary and mobile receivers for distances up to $200 \mathrm{~m}$ but differed at larger distances due to mobile detection range declining much faster than stationary detection range. The greatest difference between stationary and mobile detection efficiency was observed during 18-2 when the robot was moving away from the transmitter. During that run, mobile detection efficiency for any distance was markedly lower, even at $50 \mathrm{~m}$-the closest distance between receiver and transmitter during that run.

The GAM model explained $53.2 \%$ of the null deviance. Detection efficiency differed by direction of travel (Table 3) with more than a fivefold increase in the logodds of detection efficiency when moving toward the transmitter than away from the transmitter. Significance of distance-based smoothers suggested that variation in the shape of range curves was attributed to direction of movement and other run-specific variables not included in the model. Pitch was significant when the robot was moving toward the transmitter (with higher detection efficiency for lower pitch value, regardless of pitch direction), but not when the robot was moving away from the transmitter (Table 3a, Fig. 6c). Depth was significant when the robot was moving away from the transmitter (with better detection efficiency at shallower depths), but not when the robot was moving toward the transmitter (Table 3b, Fig. 6d). Over the ranges of depth and pitch observed, the effect of depth on detection efficiency moving away from the transmitter was greater than the effect of pitch moving toward the transmitter (Fig. 7). Overall, the highest detection efficiency was observed when the robot was navigating towards the tag with near-zero pitch, while the lowest detection efficiency was observed when the robot was navigating away from the tag and was at large depths. However, results from data checking (collinearity and concurvity; Additional file 2), variable selection (shrinkage smoother degrees of freedom and 


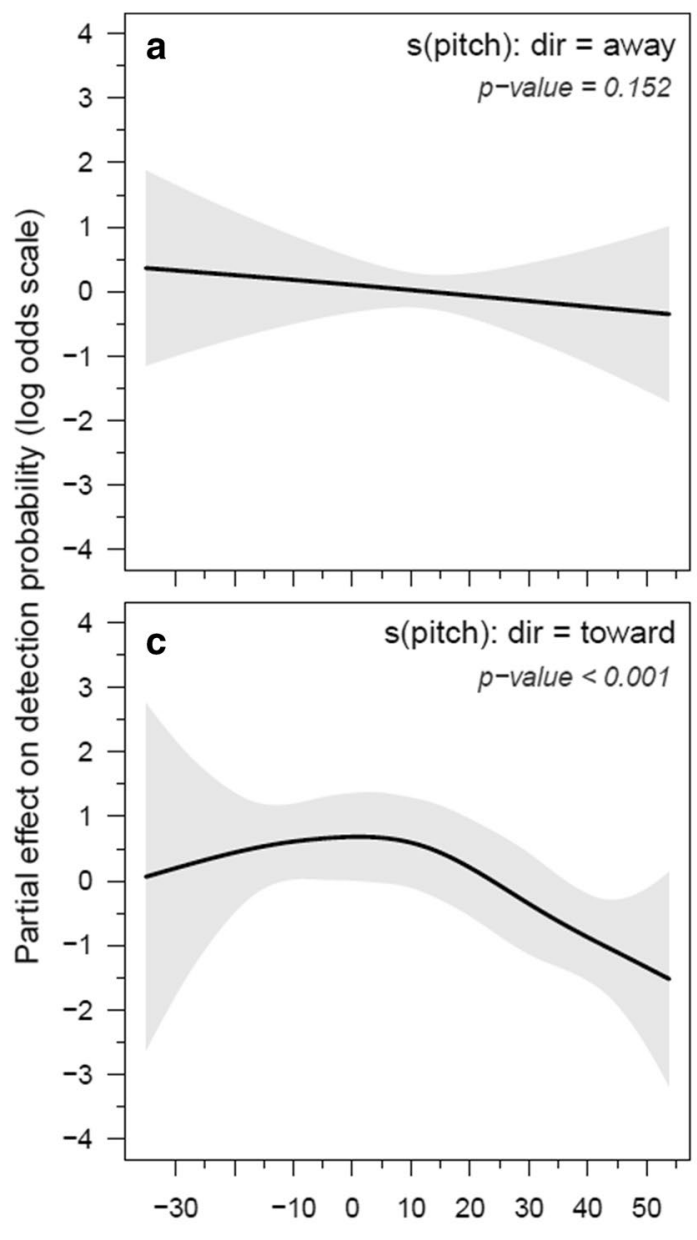

Robot pitch, degrees
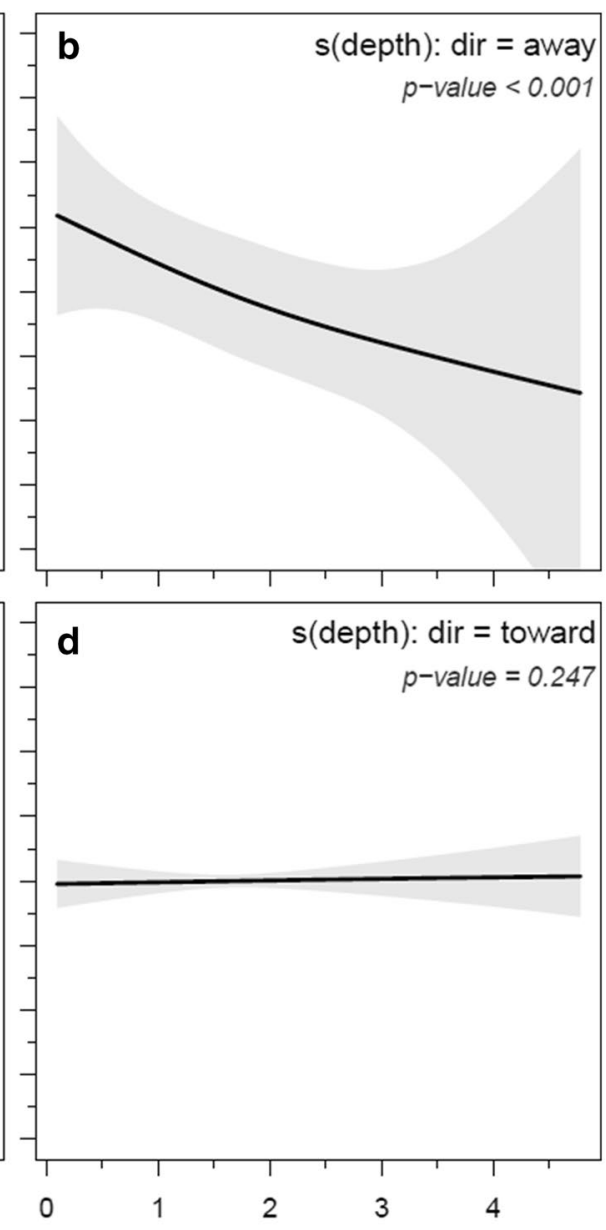

Robot depth, meters

Fig. 6 Partial effects of robot depth and pitch on detection efficiency. Estimated partial effects of robot depth and pitch on the log-odds of detection efficiency when the robot was moving away from $(\mathbf{a}, \mathbf{b})$ or toward $(\mathbf{c}, \mathbf{d})$ a stationary transmitter in Higgins Lake, Michigan. Black lines are fitted values from the model. Shaded regions are $95 \%$ confidence regions

p-values), and model selection (AIC) suggested that the relationship among depth and pitch was complex. Therefore, we caution against any strong conclusions about individual effects of pitch and depth from these results.

\section{Discussion}

Understanding detection efficiency of telemetry receivers is essential for designing and conducting a successful animal tracking project [4]. Although an animal location can be derived from detection time differences among multiple hydrophones [27], the location of a receiver at the time of detection is often used to represent the general location of a tagged animal at time of detection for presence-absence data. Data describing the effect of distance between transmitter and receiver on detection efficiency are useful for interpreting spatial ambiguity or uncertainty around detection locations, but is not commonly collected [28]. Moreover, receivers are often assumed omnidirectional, though several processes contributing to directional or non-uniform detection areas have been described [29]. Decreased detection efficiency when the robot was moving away from the transmitter was not unexpected due to potential shielding of the signal based on position (bottom-mounted) and orientation (forward-facing) of the receiver on the robot and the importance of line-of-site to acoustic detection. The magnitude of the effect, however, has important implications for the ability of an AUV in this configuration to detect tagged fish and for inferences of fish locations based on detection data.

Our results suggested that both depth and pitch can influence detection efficiency, even under a narrow 


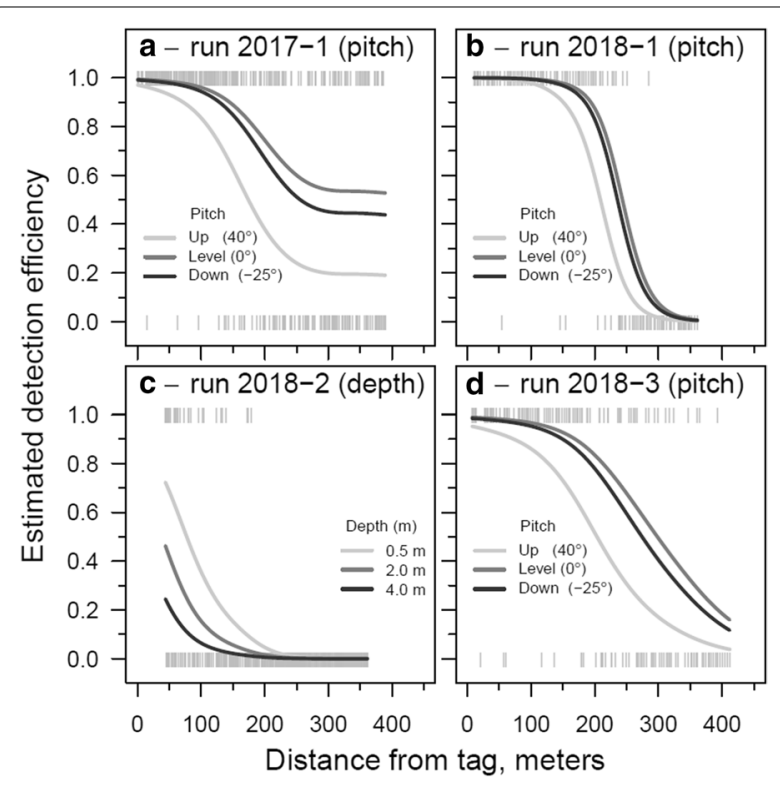

Fig. 7 Detection efficiency as a function of distance for different depth and pitch values. Estimated detection efficiencies for acoustic receivers affixed to gliding robotic fish GRACE in Higgins Lake, Michigan, during field tests in which evidence (GAM model results) suggested that detection efficiency was influenced most by depth when the robot was moving away from the transmitter (c) and pitch when the robot was moving toward the transmitter $(\mathbf{a}, \mathbf{b}, \mathbf{d})$. Lines are fitted values from the model with depth $=2 \mathrm{~m}(\mathbf{a}, \mathbf{b}, \mathbf{d})$ and pitch $=0^{\circ}$ from horizontal (c)

scope of environmental conditions. Depth and pitch are critical control parameters of AUVs that are carefully programmed to ensure mission success in the face of environmental and energetic constraints. When the objective is to detect acoustic-tagged fish, operational adjustments may be needed to achieve favorable balance among detection efficiency and other operational processes (e.g., navigation, communication). Vertical gradients of environmental variables known to affect acoustic signals in water (e.g., salinity, temperature, suspended particulates, entrained air) exist in most aquatic systems, but we were not aware of any such gradients during this study. Although lack of environmental heterogeneity may limit application of these results to other systems, it may have improved our ability to identify relatively small effects of depth and pitch on detection efficiency by minimizing background variability during our study. Moreover, observed variability that is not environmentally driven may be related to variables that can be controlled or modified.

We hypothesize that decreasing detection efficiency from the surface to $4 \mathrm{~m}$ depth when moving away from the transmitter was driven by shielding of the signal by the body of the robot at depth. As described above, this explanation seems reasonable based on position and orientation of the receiver on the robot. If true, then the depth variable used in our analysis may be a proxy for the difference in depth between the hydrophone and transmitter. Although the range in depth difference between receiver and transmitter in our tests (receiver ranged 0 to $4 \mathrm{~m}$ above the tag) may be representative of some shallow environments, potential clearly exists for much greater vertical separation between transmitter and receiver in many aquatic systems. For an AUV with bottom-mounted receiver, shielding effects are expected to be largest when the vehicle is deeper than a tagged fish and smallest when the vehicle is shallower than the tagged fish. Thus, effects of shielding may be minimized by operational parameters (e.g., depth range) based on knowledge of the ecology of the target organisms (i.e., remaining near the surface for pelagic fish) or structural changes to the vehicle (i.e., positioning the receiver on top of the AUV for surface-oriented fish).

Although the mobile receiver on the gliding robotic fish did not perform as well as stationary receivers throughout the entire range tested, detection efficiency over shorter distances (300 $\mathrm{m}$ or less) are likely still adequate for some active tracking needs. In practice, the distance at which a transmitter is reliably detected can vary considerably due to hardware and software differences and environmental conditions. Future work should seek to determine if differences between the robot-mounted receiver and stationary receivers are caused by characteristics of the robot (e.g., electrical or mechanical noise) or interaction of the robot with the environment (e.g., turbulence of flow over the hydrophone). For example, future work might seek to determine if low detection efficiency while ascending (pitched up) was associated with noise from the tail motor or increased turbulence on the receiver during tail actuation. Regardless of future improvements, however, knowledge of the robotmounted detection efficiencies will be useful for planning future missions, including active tracking with a network of AUVs.

While direct comparison of these results to similar work using the Slocum glider in [7] and Wave Glider in [8] in saltwater is difficult, the detection efficiency curves obtained here can further improve our understanding of such systems. Our obtained detection efficiency results when the hydrophone was facing towards the tag over short distances of $100 \mathrm{~m}(>80 \%)$ are close to those reported in [8] (50-90\%), and are higher than those reported in [7] (40-0\%). These results highlighted the significance of alignment between transmitter and receiver for a forward-facing receiver, and can help explain the 
lower detection efficiency observed in [7], as it could be due to occasional shielding as well as other environmental differences. These result also supported the observed improvement of detection efficiency for the vertically mounted receivers compared to the forward-facing receiver in [7], as forward-facing receivers are more susceptible to shielding of acoustic signals.

Although our results add to knowledge of AUV performance as receiver platforms, much variation in detection efficiency remained unexplained in our analysis. Unfortunately, we were not able to account for the influence of the environmental variables (e.g., wind, water temperature, ambient noise) on the results because availability of these data were limited. Our observational data set did not have sufficient replication (multiple runs) over environmental variables (e.g., wind, ambient noise, thermal stratification) to explore this aspect. Future work should seek to obtain a balanced study design with replicate runs over a range of environment variables, so that one can attribute variation in the detection efficiencies to those variables.

\section{Conclusion}

We considered parameters that affect the detection efficiency of mobile receivers mounted on AUVs through a series of trials using a gliding robotic fish, in which a forward-facing acoustic receiver was fixed to the robot's hull. While the detection efficiency of the robotmounted receiver was expected to be lowered when the receiver was pointed away from the tag, the impact of this effect was significant. Results suggested that much of the observed variation may be related to shielding of the signal by the robot body depending on the positions and orientation of the hydrophone relative to the transmitter.

These results inform hardware, software, and operational changes to gliding robotic fish that will improve detection efficiency. As an example, tag-tracking controllers should consider the directionality of the receiver, as well as the relative position of the tag with respect to the receiver. Other options to mitigate the shielding effect include the use of vertically mounted receivers, pointing upwards or downwards [7, 12], or using two bidirectionally mounted receivers (forwardand rear-facing). We hypothesize that such configurations could still suffer from reduced detection efficiency due to shielding, and knowledge of the ecology of the target organisms should be considered to guide the positioning of the receivers.

Data on the size and shape of detection efficiency curves for gliding robotic fish will be useful for planning future missions and should be relevant to other AUVs for telemetry. While the detection efficiency of the mobile receiver, when facing the tag, matched that of stationary receivers for distances of less than $300 \mathrm{~m}$, these distances are still adequate for several active tracking applications using networks of these AUVs. Future work should seek to determine if differences between the robot-mounted receiver and stationary receivers are due to characteristics of the robot or interaction of the robot with the environment. Finally, future studies should use a balanced study design with replicate runs over a range of environment variables and compare the detection efficiency using different AUVs.

\section{Supplementary information}

\section{Supplementary information accompanies this paper at https://doi. org/10.1186/s40317-020-00219-7.}

Additional file 1. Summaries of environmental noise, water temperature, and receiver tilt data collected during field tests of gliding robotic fish in Higgins Lake, 2016-2018.

Additional file 2. Data and model checking methods and results for generalized additive model fit to detection data collected during field tests of gliding robotic fish in Higgins Lake, 2016-2018.

\section{Acknowledgements}

We would like to thank Chris Wright and Henry Thompson from USGS for their help during the field trials in Higgins Lake. This work was supported in part by the U.S. National Science Foundation (ECCS 1446793, IIS 1848945), the Great Lakes Fishery Commission (2014_Tan_44058), and the United States Geological Survey Innovation Center for Earth Sciences. This work also was supported in part by funds from the Great Lakes Fishery Commission by way of Great Lakes Restoration Initiative appropriations (GL-00E23010). This paper is Contribution 66 of Great Lakes Acoustic Telemetry Observation System (GLATOS). Any use of trade, firm, or product names is for descriptive purposes only and does not imply endorsement by the US Government.

\section{Authors' contributions}

OE and $\mathrm{CH}$ jointly wrote the initial manuscript. OE, DC, PS, JT and XT developed the robotic platform and its navigation algorithms. $\mathrm{CH}$ analyzed the acoustic detection data. DWH and CK assisted with project development and field trials. All authors read and approved the final manuscript.

\section{Funding}

This work was supported in part by the U.S. National Science Foundation (ECCS 1446793, IIS 1848945), the Great Lakes Fishery Commission (2014_ Tan_44058), and the United States Geological Survey Innovation Center for Earth Sciences. This work also was supported in part by funds from the Great Lakes Fishery Commission by way of Great Lakes Restoration Initiative appropriations (GL-00E23010). This paper is Contribution 66 of Great Lakes Acoustic Telemetry Observation System (GLATOS).

\section{Availability of data and materials}

The data sets used and analyzed during the current study are available from the corresponding author on reasonable request.

Ethics approval and consent to participate

Not applicable.

\section{Consent for publication}

Not applicable.

\section{Competing interests}

The authors declare that they have no competing interests. 


\section{Author details}

1 Smart Microsystems Lab, Department of Electrical and Computer Engineering, Michigan State University, East Lansing, MI 48824, USA. ${ }^{2}$ U.S. Geological Survey, Hammond Bay Biological Station, 11188 Ray Rd, Millersburg, MI 49759, USA. ${ }^{3}$ Great Lakes Science Center, U.S. Geological Survey, 1451 Green Rd, Ann Arbor, MI 48105, USA. ${ }^{4}$ Center for Systems Integration and Sustainability, Michigan State University, East Lansing, MI 48824, USA.

Received: 6 June 2020 Accepted: 12 October 2020 Published online: 24 October 2020

\section{References}

1. Hussey NE, Kessel ST, Aarestrup K, Cooke SJ, Cowley PD, Fisk AT, Harcourt RG, Holland KN, Iverson SJ, Kocik JF. Aquatic animal telemetry: a panoramic window into the underwater world. Science. 2015;348(6240):1255642.

2. O'Dor RK, Stokesbury MJ. The Ocean Tracking Network--adding marine animal movements to the global ocean observing system. In: Tagging and Tracking of Marine Animals with Electronic Devices, Springer, 2009, pp. 91-100.

3. Welch DW, Boehlert GW, Ward BR. POST - the Pacific Ocean salmon tracking project. Oceanol Acta. 2002;25(5):243-53.

4. Heupel MR, Semmens JM, Hobday AJ. Automated acoustic tracking of aquatic animals: scales, design and deployment of listening station arrays. Mar Freshw Res. 2006;57(1):1-13.

5. Cooke SJ, Iverson SJ, Stokesbury MJ, Hinch SG, Fisk AT, VanderZwaag DL, Apostle R, Whoriskey F. Ocean Tracking Network Canada: a network approach to addressing critical issues in fisheries and resource management with implications for ocean governance. Fisheries. 2011;36(12):583-92.

6. Krueger CC, Holbrook CM, Binder TR, Vandergoot CS, Todd HA, Hondorp DW, Nate N, Paige K, Riley SC, Fisk AT, Cooke SJ. Acoustic telemetry observation systems: challenges encountered and overcome in the Laurentian Great Lakes. Can J Fish Aquat Sci. 2018;75(10):1755-63.

7. Oliver MJ, Breece MW, Haulsee DE, Cimino MA, Kohut J, Aragon D, Fox DA Factors affecting detection efficiency of mobile telemetry Slocum gliders. Animal Biotelemetry. 2017;5(1):14.

8. Cimino M, Cassen M, Merrifield S, Terrill E. Detection efficiency of acoustic biotelemetry sensors on Wave Gliders. Animal Biotelemetry. 2018;6(1):16.

9. Mordy CW, Cokelet ED, De Robertis A, Jenkins R, Kuhn CE, Lawrence-Slavas N, Berchok CL, Crance JL, Sterling JT, Cross JN, Stabeno PJ. "Advances in ecosystem research: Saildrone surveys of oceanography, fish, and marine mammals in the Bering Sea. Oceanography. 2017;30(2):113-5.

10. Oliver MJ, Breece MW, Fox DA, Haulsee DE, Kohut JT, Manderson J, Savoy T. Shrinking the haystack: using an AUV in an integrated ocean observatory to map Atlantic Sturgeon in the coastal ocean. Fisheries. 2013;38(5):210-6

11. Breece MW, Fox DA, Dunton KJ, Frisk MG, Jordaan A, Oliver MJ. Dynamic seascapes predict the marine occurrence of an endangered species: Atlantic Sturgeon Acipenser oxyrinchus oxyrinchus. Methods Ecol Evol. 2016;7(6):725-33.

12. Haulsee DE, Breece MW, Miller DC, Wetherbee BM, Fox DA, Oliver MJ. Habitat selection of a coastal shark species estimated from an autonomous underwater vehicle. Mar Ecol Prog Ser. 2015;528:277-88.
13. Clark CM, Forney C, Manii E, Shinzaki D, Gage C, Farris M, Lowe CG, Moline M. Tracking and following a tagged leopard shark with an autonomous underwater vehicle. Journal of Field Robotics. 2013;30(3):309-22.

14. Grothues TM, Dobarro J, Ladd J, Higgs A, Niezgoda G, Miller D. Use of a multi-sensored AUV to telemeter tagged Atlantic sturgeon and map their spawning habitat in the Hudson River, USA. In: Autonomous Underwater Vehicles, 2008. AUV 2008. IEEE/OES, 2008.

15. Carlon R. Tracking tagged fish using a wave glider, In: OCEANS 2015 MTS/IEEE Washington, Washington, DC, 2015

16. D. Shinzaki, C. Gage, S. Tang, M. Moline, B. Wolfe, C. G. Lowe and C. Clark, "A multi-auv system for cooperative tracking and following of leopard sharks. In: 2013 IEEE International Conference on Robotics and Automation, Karlsruhe, Germany, 2013.

17. Webb DC, Simonetti PJ, Jones CP. SLOCUM: An underwater glider propelled by environmental energy. IEEE J Oceanic Eng. 2001;26(4):447-52.

18. Woithe HC, David B, Ulrich K. Improving Slocum Glider dead reckoning using a Doppler Velocity Log. In: OCEANS'11 MTS/IEEE KONA, Waikoloa, 2011.

19. Zhang F, Tan X. Gliding robotic fish and its tail-enabled yaw motion stabilization using sliding mode control. In: ASME 2013 Dynamic Systems and Control Conference, Palo Alto, 2013.

20. Zhang F, Wang J, Thon J, Thon C, Litchman E, Tan X. Gliding robotic fish for mobile sampling of aquatic environments: In: 2014 IEEE 11 th International Networking, Sensing and Control (ICNSC), Miami, 2014.

21. Zhang F, Ennasr O, Tan X. Gliding robotic fish: an underwater sensing platform and its spiral-based tracking in $3 \mathrm{~d}$ space. Marine Technol Soci J. 2017:51(5):71-8.

22. Zhang F, Ennasr O, Litchman E, Tan X. Autonomous sampling of water columns using gliding robotic fish: algorithms and harmful-algae-sampling experiments. IEEE Syst J. 2016;10(3):1271-81.

23. "Global Forecast System (GFS)," National Oceanic and Atmospheric Administration (NOAA). https://www.ncdc.noaa.gov/data-access/model -data/model-datasets/global-forcast-system-gfs.

24. Zuur AF, leno EN, Walker NJ, Saveliev AA, Smith GM. Mixed effects models and extensions in ecology with R, Springer Science \& Business Media, 2009.

25. Wood SN. Fast stable restricted maximum likelihood and marginal likelihood estimation of semiparametric generalized linear models. J Royal Stat Soc Ser B. 2011;73(1):3-36.

26. R Core Team, R. A language and environment for statistical computing. Vienna: R Foundation for Statistical Computing; 2019

27. Espinoza M, Farrugia TJ, Webber DM, Smith F, Lowe CG. Testing a new acoustic telemetry technique to quantify long-term, fine-scale movements of aquatic animals. Fish Res. 2011;108(2-3):346-71.

28. Kessel ST, Cooke SJ, Heupel MR, Hussey NE, Simpfendorfer CA, Vagle S, Fisk AT. A review of detection range testing in aquatic passive acoustic telemetry studies. Rev Fish Biol Fisheries. 2014;24(1):199-218.

29. Kessel S, Webber HND, Gruber S, Young J, Smale M, Fisk A. Close proximity detection interference with acoustic telemetry: the importance of considering tag power output in low ambient noise environments. Animal Biotelemet. 2015:3(1):5.

\section{Publisher's Note}

Springer Nature remains neutral with regard to jurisdictional claims in published maps and institutional affiliations. 